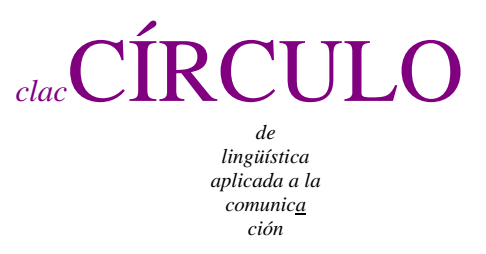

$65 / 2016$

\title{
ARGUMENTACIÓN E IMAGEN PERIODÍSTICA EN LA EVALUACIÓN AXIOLÓGICA DEL DESEMPEÑO DE LA FUNCIÓN PÚBLICA
}

\author{
Pablo Porto López y Cristián Santibáñez \\ Universidad de Buenos Aires, Universidad Diego Portales \\ pabloportolopez en gmail com, cristian.santibanez en udp cl
}

Resumen

En este trabajo proponemos un análisis multimodal del discurso argumentativo periodístico que combina imagen y componente verbal. Se analizan dos casos de noticias internacionales que han causado revuelo internacional. Las herramientas metodológicas utilizadas provienen de la teoría argumentativa contemporánea, el análisis semiótico-discursivo y la gramática funcional para el análisis de imágenes. El análisis nos permitirá concluir que, cuando los intereses socio-económicos corporativos de la compañía periodística se ven afectados por alguna razón, las líneas editoriales despliegan una posición argumentativa tajante y una estrategia sutil y elaborada desde la

Porto López, Pablo, y Cristián Santibáñez. 2016.

Argumentación e imagen periodística en la evaluación axiológica del desempeño de la función pública

Círculo de Lingüística Aplicada a la Comunicación 65, 291-316.

http://www.ucm.es/info/circulo/no65/porto.pdf

http://revistas.ucm.es/index.php/CLAC

http://dx.doi.org/10.5209/rev_CLAC.2016.v65.51989

(C) 2016 Pablo Porto López y Cristián Santibáñez.

Círculo de Lingüística Aplicada a la Comunicación (clac)

Universidad Complutense de Madrid. ISSN 1576-4737. http://www.ucm.es/info/circulo 
perspectiva semiótica y estética. Cuando se trata de evaluar y controlar el desempeño de la función pública, la imagen periodística toma el aparente rol del ciudadano crítico.

Palabras clave: argumentación, discurso, multi-modalidad, periodismo, retórica de la imagen.

\begin{abstract}
In this paper we propose a multimodal analysis of the journalistic argumentative discourse that combines image and verbal components. Two international news items that have caused impact internationally are analyzed. The methodological tools used come from contemporary argumentative theories, semiotic-discursive analysis, and the functional grammatical analysis of images. The resulting analysis will allow us to conclude that, when the corporative socio-economics interests of the journalistic company are affected, the editorials display both a sharp argumentative position and a subtle and elaborated semiotic and aesthetic strategy. When it is about evaluating and controlling the administrative function, the journalistic image apparently takes the role of a critical citizen.
\end{abstract}

Keywords: argumentation, discourse, journalism, multi-modality, rhetoric of image.

Índice

1. Introducción 292

2. Griesa y los “fondos buitre" 295

3. Merkel y la NSA 307

4. Conclusiones 314

Bibliografía 314

\title{
1. Introducción
}

Que una imagen pueda albergar o desencadenar una argumentación es un problema que confronta a diversas perspectivas teóricas. El problema remite, por un lado, a qué se considera como argumentación -una práctica orientada a la toma de decisión y a la acción (Perelman 1989; Tindale, 2004; Toulmin, 2007; Walton, 2008), una propiedad de la lengua (Anscombre y Ducrot 1994), un actividad verbal y social destinada a 
promover la aceptabilidad -crítica- de un punto de vista (van Eemeren y Grootendorst, 2004), por nombrar algunas de sus conceptualizaciones-; y, por otro lado, el problema se expande hacia el tipo y alcance de operaciones significantes que se supone pueden vehiculizar o producir las imágenes. Entre la postura que sostiene la irreductibilidad de los modos semióticos, anclada en aquello que hay de intraducible entre lo visual y lo verbal, y la que mantiene que existe una equivalencia (o equivalencia funcional) entre ambos, se encuentran una serie de perspectivas teóricas cuyo posicionamiento respecto de esta cuestión no siempre es fácil de determinar, y que este trabajo comentará en parte.

Por ejemplo, van der Hoven (2011), que utiliza la noción de equivalencia funcional, advierte que no se trata de un concepto teóricamente bien definido sino esencialmente de uno con fines heurísticos para indicar un posicionamiento similar entre un texto visual y uno verbal cuando estos apelan a un cuerpo común de conocimiento en la reconstrucción de la argumentación representada. En un sentido similar, van Belle (2010) sostiene que si bien lo verbal y lo visual probablemente posean zonas propias de intraducibilidad, tienen asimismo mucho en común.

Ya no desde una perspectiva argumentativa, y poniendo un énfasis mayor en aquello que es irreductible a cada modo semiótico, Kress y van Leeuwen señalan que "cada uno de los modos afirma en sus propios términos en relación con una gama coherente de significados” (2002: 364) y que "las viejas nociones ya sean de sentido común o teóricas, como ‘ilustración’ (imágenes ‘ilustrando’ textos verbales) o ‘explicación’ (palabras ‘explicando’ diagramas) ya no son una descripción adecuada de las relaciones entre palabras e imágenes” (1996: 53). Benveniste había señalado esta diferencia fundamental al referir a la doble significancia (semiótica y semántica) de la lengua, al tiempo que caracterizó a la obra de arte (literaria, pictórica, musical) como una semántica sin semiótica, debido a la ausencia de unidades diferenciales y oponibles que formen sistema del modo que lo hacen los signos lingüísticos (1974: 47-69).

En tanto el análisis proceda a través de la verbalización acrítica del mensaje de las imágenes sin una teoría y una metodología que permitan interpretarlas sistemáticamente en su condición de tales, se estará, en mayor o menor medida, manejando una teoría ingenua de la equivalencia funcional. Tal vez no siempre sea posible evitar esto, pero es 
preciso permanecer conscientes de la operación de traducción, de ninguna manera automática ni trasparente, que presupone.

El presente trabajo pretende ser una contribución a este debate a partir del análisis de una modalidad específica de uso de las fotografías en el marco del discurso periodístico. Se estudiará un modo de empleo de las imágenes que señala, de manera figurada, una transgresión o una falta en el desempeño de los funcionarios públicos. El interés de este tipo de operación en los ejemplos que se analizan radica en que se efectúa a través de medios visuales, en un caso a través de la imagen de manera excluyente y en el otro en combinación con texto escrito, y sin recurrir al trucaje o al montaje, ni a lo testimonial. Dicho de otra forma, en las fotografías estudiadas no se observa, por ejemplo, al funcionario en el acto efectivo de cometer una falta de conducta (lo que sería un caso de fotografía testimonial) así como tampoco se ha alterado en ellas la materialidad del texto fotográfico ni preparado ex profeso una escenificación para capturar luego la imagen (lo que correspondería al trucaje y al montaje respectivamente). En el primer caso, se analizará una fotografía del juez Thomas Griesa, que es el encargado de arbitrar en la negociación entre Argentina y los fondos tenedores de bonos de deuda del país que no ingresaron en los canjes de reestructuración llevados a cabo por el país; esta fotografía ha circulado, entre otros espacios, en los noticieros de la televisión pública argentina en 2014, en rotación permanente con otras imágenes del juez, y que es utilizada al momento de presentar avances sobre el estado de la causa. El otro texto analizado es un artículo online del periódico inglés The Guardian, de julio de 2013, acerca del escándalo de las escuchas telefónicas en Alemania que involucraron al gobierno de Angela Merkel, y que fuera una de las tantas ramificaciones de la filtración de los programas secretos de vigilancia de la NSA (National Security Agency) realizada por el ex técnico de inteligencia Edward Snowden.

Como ya se apuntó, ambas imágenes no expresan la transgresión de manera literal, sino que se valen de operaciones de figuración retórica, las cuales son conceptualizadas, especialmente desde Perelman, no como un simple ornato estilístico sino como un modo de argumentar, por más elíptico o condensado que pueda ser. La orientación argumentativa de las imágenes que aquí se analizan, no obstante, no puede inferirse cabalmente desde la inmanencia del sentido de las figuras retóricas que allí se despliegan, sino que en ambas se observa un deslizamiento, una segunda operación 
significante, que tiene lugar en un doble plano: de una parte, a partir de la interrelación de dichas operaciones retorizantes con presupuestos relativos a lo que se considera el correcto desempeño del cargo público correspondiente en cada caso a la personalidad retratada y, por otra parte, por su relación con el cotexto y el contexto en el que aparece inserta la fotografía como movida argumentativa. A continuación entonces el análisis de lo que aquí se afirma.

\section{Griesa y los "fondos buitre"}

En la primera fotografía (FIGURA 1) se ve al juez estadounidense Thomas Griesa en su despacho de Manhattan. Varios indicios locativos sugieren esto: los edificios que se ven a través de la ventana remiten a una zona urbana céntrica, la bandera de Estados Unidos es asimismo un indicio de que se trata de una dependencia del Estado, pero fundamentalmente el hecho de que se está colocando la toga de juez con ayuda de otra persona, de la que se ven solamente los brazos.

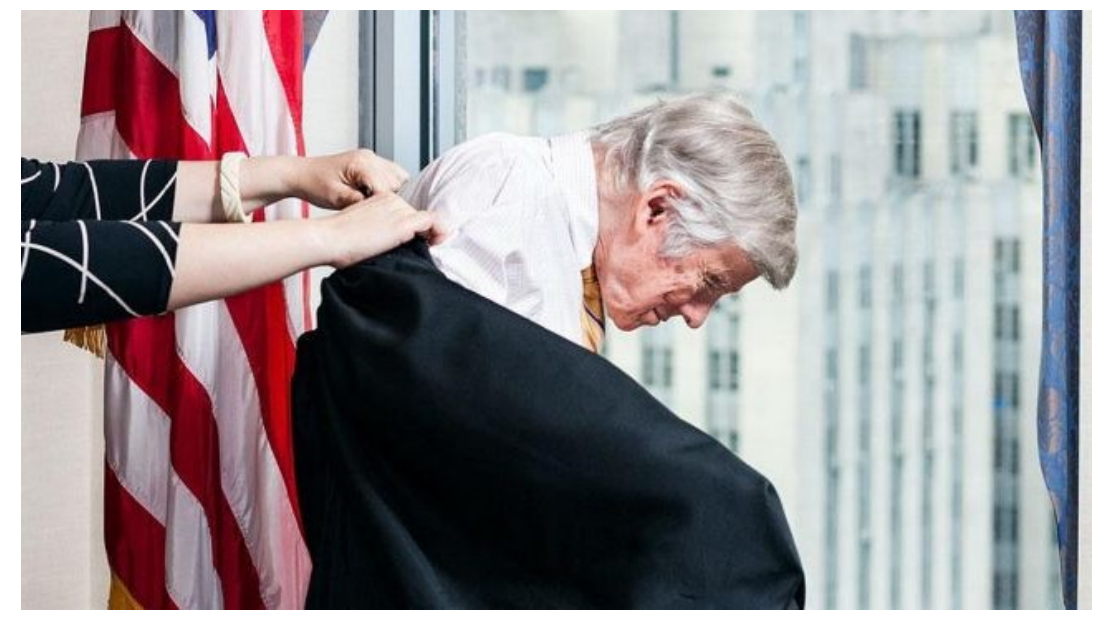

Figura 1 - Fotografía de Thomas P. Griesa en la sala de su despacho en Manhattan, Nueva York

El sentido global de la fotografía se estructura a partir de una operación metafórica. La metáfora ha sido definida como la figura de la semejanza (Meyer 2013), figura en la que se establece una relación de identidad entre dos elementos. Aquí, la fotografía trabaja sobre la semejanza física entre Griesa y los buitres: la pose encorvada, el cuello con joroba, la cabeza blanca y, finalmente, la toga negra a modo del ala. Sin embargo, el poder argumentativo de la imagen no se deriva de manera directa de esta metáfora; pese a que resulta innegable que todos estos elementos refuerzan la interpretación de aquella 
en tanto que tienen la misma orientación en detrimento de Griesa. Lo que tiene lugar aquí es un desplazamiento de la operación de metaforización a partir de la intervención de otros elementos de diverso orden: algunos presentes en la propia imagen, otros que corresponden al contexto (que comprende tanto a los presupuestos compartidos por enunciador y destinatario como a la producción discursiva relativa al juicio que excede a la fotografía en cuestión) ${ }^{1}$ y, finalmente, otros relativos a la tópica de la comunidad que interpreta la fotografía. Es necesario reponer estos elementos, que son exteriores a la fotografía pero que son tematizados por ella, para poder captar su orientación argumentativa.

El caso de los llamados "fondos buitre" (vulture funds) ha instalado un animado debate tanto en la Argentina como a nivel latinoamericano e internacional, motivando tomas de posición por parte de diferentes países y actores sociales, que ha desembocado en la conformación de una comisión en el seno de las Naciones Unidas para la investigación de su accionar. Los “fondos buitre”, con los cuales mantiene su disputa la Argentina, son fondos de cobertura o de alto riesgo (hedge funds) que luego de haber comprado bonos de deuda soberana de dicho país a precios muy bajos, como resultado del default en 2001, rechazaron las condiciones de pago que la inmensa mayoría (el 92,4\%) de los bonistas acordó con la Argentina durante las negociaciones de reestructuración de 2005 y 2010. En su lugar, los responsables de estos fondos llevaron el caso a la corte del distrito de Nueva York, donde fue tomado por el juez Thomas Griesa. ${ }^{2}$

Los “fondos buitre” reciben este apelativo de carácter también metafórico debido al empleo de lo que sus detractores consideran “tácticas carroñeras”, consistentes en “acechar” y “depredar” empresas o países con severos problemas financieros, o

\footnotetext{
1 “Llamemos ‘contexto’ al saber compartido del que creen disponer los interlocutores acerca de la cuestión en juego. . . Ese saber mutuo, común, crea una situación que permite silenciar muchas respuestas sin dejar de movilizarlas” (Meyer, 2013: 105). El contexto, dentro de la teoría de Meyer, tiene una función eminentemente de reducción de la problematicidad: "Basados en un contexto, es decir, en un saber compartido que sabemos que el otro posee y que él sabe que lo sabemos, podemos ahorrarnos ese proceso de regresión interrogativa (ad infinitum)” (116).

${ }^{2}$ Sumado a las alegaciones del gobierno argentino de que el país no cuenta con los recursos para el pago conjunto a los acreedores reestructurados y a los que no ingresaron en el canje (hold-out), el fallo de Griesa en contra de Argentina hace peligrar la quita de la deuda conseguida para el restante $92,4 \%$ de los bonistas, puesto que la cláusula RUFO (Rights Upon Future Offers) de los acuerdos de reestructuración determina que no se podrán ofrecer mejores condiciones de pago en canjes futuros sin reconocer al mismo tiempo esas mismas condiciones para todos los que ingresaron en los canjes previos. De allí la importancia caso, puesto que pone en peligro el proceso completo de reestructuración de la deuda que el país lleva adelante desde hace más de diez años.
} 
directamente en quiebra, para la obtención de rentabilidades extraordinarias en sus negocios. A través de la compra de bonos a bajo precio (los "bonos basura"), seguida de una demanda judicial al deudor en la que se reclama el pago del importe nominal de los bonos, persiguen enormes ganancias sin consideraciones por las consecuencias políticas, sociales o económicas que de ello pudieran derivarse. Representan, en este sentido, lo peor del capital financiero especulativo.

El principio de la metáfora es, según Meyer (2013), "la posibilidad de instaurar una identidad entre dos términos, encajando en lo implícito una tercera propiedad común que justifica esta identidad" (152). Con el ejemplo de la metáfora verbal "Ricardo es un león”, la identidad que se postula entre el rey inglés y el animal (que es además el rey de la selva), se sostiene por el rasgo que tienen en común: el valor. Esta lectura de la metáfora se deriva en buena medida de la perspectiva del Grupo $\mu$ (1987) que la concibe como una doble sinécdoque (la figura de la parte por el todo o del todo por la parte) en la que tiene lugar una operación complementaria de adición y supresión. Primero, una sinécdoque generalizante, que en el caso de los "fondos buitre" va de fondos de cobertura a prácticas carroñeras, seguida de una sinécdoque particularizante, de prácticas carroñeras a buitre. Del mismo modo, sería posible explicar este procedimiento a partir del locus de analogía (Pollaroli, 2012), como un paralelismo que se establece entre dos elementos que pertenecen a la misma categoría: la de lo valiente para el caso de Ricardo y los leones, la de lo carroñero para el caso de los fondos de cobertura y los buitres.

Volviendo al texto visual analizado, la interpretación de la metáfora en la fotografía de Griesa a partir de la categoría o de los semas compartidos entre los que ha establecido el puente de la doble sinécdoque, lleva a proyectar sobre el juez aquellos atributos negativos asociados al ave: especialmente el carácter carroñero, de animal que acecha a sus víctimas cuando éstas se hallan desprotegidas o cercanas a la muerte. Esto llevaría a sospechar de la naturaleza inmisericorde del juez, especialmente respecto de la que constituye la parte más débil en el enfrentamiento legal, y que posiblemente se pudiera manifestar en una sentencia desfavorable para ella.

Si bien es ésta la metáfora que pone en escena la fotografía, es su interjuego con la otra metáfora de los "fondos buitre", de carácter contextual, la que le confiere su fuerza 
argumentativa. La primera está basada en una semejanza física, la de Griesa con los buitres, que es interior a la imagen e instaurada por ella. La otra, la metáfora de los fondos de cobertura como buitres, se halla fundada no en un parecido físico (los "fondos buitre” no se parecen a los buitres), sino en el carácter de sus prácticas financieras, asociadas a lo carroñero y la depredación, que es exterior a la imagen y de la que ésta solamente se sirve en el contexto específico de reconocimiento en que se inserta. Esa doble operación, semejanza física instituida por la imagen y semejanza metafórica instaurada a partir de hábitos de comportamiento que son exteriores y anteriores a la misma (y que refieren a un actor que no está presente en el texto visual), llevan a identificar a Griesa con los "fondos buitre" -en un sentido hasta casi fortuito como sucede en la homonimia, pues ambos son buitres pero no lo son por medio de la misma operación significante. Y es esta operación de la que extrae la imagen su orientación argumentativa: la identificación del juez con una de las partes del caso.

El doble movimiento metafórico cuyo resultado conduce a identificar a Griesa con los “fondos buitre”, funciona a nivel axiológico como una crítica del proceder del magistrado. ¿Cómo se explica la orientación argumentativa que asume el texto visual? A partir de la incompatibilidad que presupone tener relaciones o intereses en común con una de las partes para el correcto desempeño de las funciones de un juez, de quien se exige una postura desapasionada y neutral en la aplicación de la ley. A continuación, se esquematiza este doble procedimiento a partir de una forma inferencial para el primer movimiento de identificación entre Griesa y los “fondos buitre”; y luego, por medio del modelo de Toulmin, se despliega el proceso argumentativo de la segunda operación, que toma como dato la conclusión del primer esquema de identificación del juez con la parte:

Inferencia de $1^{a}$ figura (construido a partir de la doble metáfora):

Los (fondos) buitres son parte en el juicio (M es P)

Griesa es buitre (S es M)

Griesa es parte en el juicio (S es P) 
Esquema mayor (que le da su orientación argumentativa a la imagen):

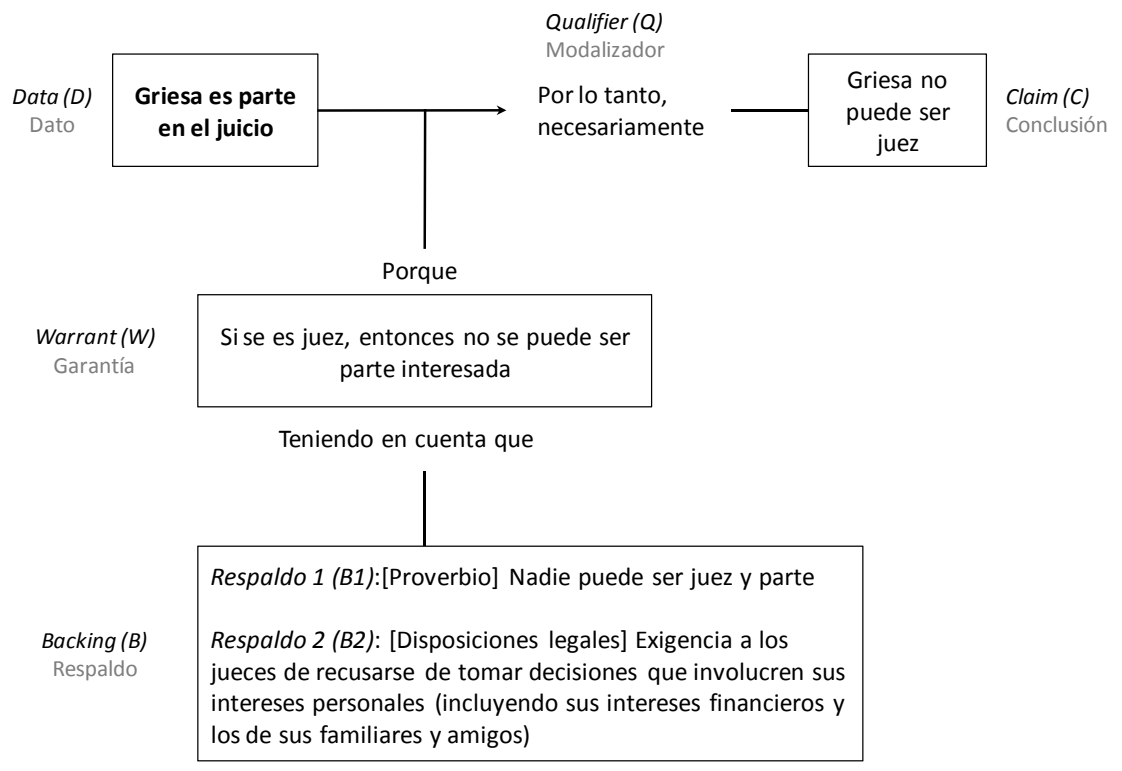

Esquema 1 - Reconstrucción argumentativa de la Fotografía 1 según el modelo de Toulmin

Interpretada de este modo, la fotografía escenificaría un caso de conflicto de intereses. Por eso, la imagen no solamente parece señalar que la decisión de Griesa favorecerá a los "fondos buitre", sino que rechaza la legitimidad misma de dicho fallo en tanto que no están dadas las condiciones dispuestas por la ley para un juicio justo. Esto, que la imagen pone en escena a través de una operación retorizante y en última instancia falaz, encuentra sin embargo eco en una serie de discursos, construidos a partir de una argumentación basada en lo razonable, que señalan las relaciones del juez con la parte acusadora. ${ }^{3}$

Aquello que permite salvar la distancia entre el dato que presenta la imagen y la conclusión a la que apunta, es lo que Toulmin denomina garantía (warrant). Se trata de un

\footnotetext{
${ }^{3}$ En una noticia del periódico argentino Página/12 titulada “Toga de juez, pero con pico y plumaje de buitre” se reproduce un fragmento de la transcripción taquigráfica de una audiencia de junio de 2014 que según el diario "permite entender la relación entre Griesa y los fondos buitre: aquél pregunta qué medidas necesitan éstos, y hasta les encarga redactarlas". Vale la pena citar una parte del diálogo entre los abogados de los fondos de cobertura y el juez Griesa que publica Página/12: 'Señor Cohen, ¿qué necesita además de las medidas ya instrumentadas?’, le preguntó el juez Thomas Griesa al abogado representante de los fondos buitre NML Capital y Elliott. 'La presidenta Kirchner y el ministro de Economía Kicillof dijeron que tomaron medidas para poner en práctica un plan para pagar a los tenedores de deuda reestructurada en la Argentina y no pagarnos a nosotros. Por eso el plan y su puesta en práctica son una violación de su orden.' Griesa tomó la palabra: ' $Y$ no pagarnos a nosotros. ¿Dijeron eso?'. 'Sí', respondió el abogado.” Disponible en: http://www.pagina12.com.ar/diario/economia/2-249030-2014-06-20.html. Consultado el 20 de octubre de 2014.
} 
enunciado hipotético que funcionan a modo de puente (2007: 143) con la forma de "Puede suponerse (casi) con total certeza que A es B", "Un C es generalmente un D” y similares, que no necesariamente debe estar explicitado en la cadena argumentativa desplegada. De hecho, en el caso de la fotografía analizada, se trata de un elemento necesario para su interpretación pero que se encuentra solamente presupuesto. Este principio de carácter más bien formal, tiene su fundamentación en formulaciones asertivas (enunciados categóricos sobre hechos) pertenecientes a un campo discursivo o epistémico particular, lo que constituye la aportación clave de Toulmin ${ }^{4}$, y que llama respaldo (backing): en la interpretación de la imagen de Griesa, el respaldo puede extraerse tanto del mundo cotidiano del refrán (B1), ${ }^{5}$ como del campo discursivo especializado de las disposiciones legales (B2).

Rigotti (2008), por su parte, efectúa una distinción aún más tajante, si cabe, entre lo formal y lo material en la argumentación. Rigotti recupera la noción de endoxon de Aristóteles y la define como "una opinión que es aceptada por la audiencia relevante" (2008: 572). Se trata de un elemento vinculado estrechamente al contexto y a la cultura. Como tal, forma parte de lo que su Argumentum Model of Topics (AMT) identifica como el punto de partida material del argumento. En efecto, el endoxon junto con el datum (o dato), componen la dimensión material de la argumentación, cuya contrapartida procedimental se estructura a partir de la máxima como principio de carácter formal derivado del locus. ${ }^{6}$

Lo que distancia al endoxon del datum, pese a que ambos pertenecen al componente material del AMT, es que el segundo es presentado por el texto en cuestión (explicitado en la cadena argumentativa), mientras que el primero es en mayor o menor medida presupuesto por el alocutor y el alocutario; del mismo modo que el dato se explicita en el modelo de Toulmin pero no necesariamente la garantía ni el respaldo. En efecto, el

\footnotetext{
${ }^{4}$ La estructura formal de la garantía (o la premisa mayor) oculta las diferencias semánticas y epistémicas de las cuales su validez lógica no es independiente.

${ }^{5}$ Paremia que existe en español, inglés, francés, italiano y alemán entre otros idiomas, y que proviene del latín Nemo esse iudex in sua causa potest o nemo sibi sit judex.

${ }^{6}$ Esta distinción entre lo material y lo procedimental también reenvía a la ambigüedad que ya señalara Barthes en la conceptualización de los lugares comunes como un casillero de formas vacías y como una reserva de formas llenas; así, los topoi: “1) son formas vacías comunes a todos los argumentos (cuanto más vacías, más comunes); 2) son estereotipos, proposiciones repetidas muchas veces” (Barthes, 1997: 137).
} 
endoxon "no funciona como una premisa lógico-inferencial sino que funciona sólo si los interlocutores lo comparten desde un principio, o sea, si está en su common ground" (Pollaroli, 2012, p. 7). Por ello esta teoría destaca la importancia del contexto para la argumentación como algo más que la “esfera borrosa en la que la argumentación tiene lugar. [El contexto] tiene un efecto en las premisas de movidas argumentativas específicas” (Greco Morasso, 2011: 4).

En el caso de la fotografía de Griesa, el dato (“Griesa es parte en el juicio”) entra en conflicto con la idea ampliamente aceptada de que la imparcialidad en la aplicación de la ley es un valor, un principio de conducta a ser observado por el juez. Éste es el endoxon que funciona como punto de partida material del segundo argumento, y con el que entra en conflicto aquello que aparece representado por el datum a través de la doble metáfora que identifica a Griesa con los “fondos buitre”. De este modo, la figura retórica como esquema argumentativo condensado (Meyer 2013, Pollaroli, 2012) ${ }^{7}$ se inserta en un segundo esquema mayor que es en donde adquiere su orientación argumentativa.

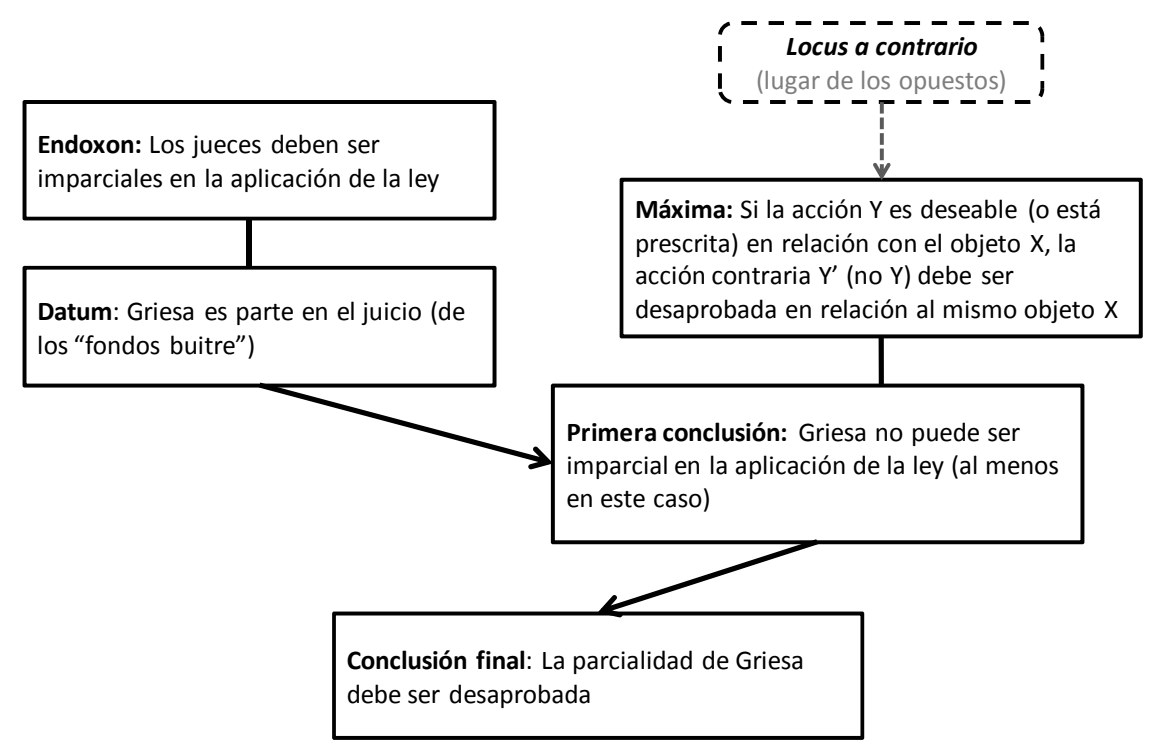

Esquema 2 - Reconstrucción argumentativa de la Fotografía 1 según el modelo de la $\mathrm{AMT}^{8}$

\footnotetext{
7 “(U)n tropo es el condensado de un argumento, una tesis que va mucho más allá del efecto de presencia” (Meyer 2013: 154).

${ }^{8}$ Para la formulación de la máxima nos basamos en la de Igor Žagar (2011: 3): "If action Y is desirable in relation to object $\mathrm{X}$, the contrary action $\mathrm{Y}^{\prime}$ ' should be disapproved of in relation to the same object $\mathrm{X}$ ”.
} 
En ambos esquemas, el de Toulmin y el de la AMT, se pone en juego un conocimiento general sobre lo que se presupone debe ser el correcto proceder de un juez. El esquema de Toulmin pone de relieve que es del campo judicial de donde se extrae el respaldo último de la garantía empleada para la argumentación. En el caso del modelo de la AMT, la expresión de la máxima, en tanto que principio inferencial abstracto, permite identificar, tal vez con más claridad, el esquema que despliega la argumentación pictórica. Al valerse del lugar de los opuestos, se pone en escena una cualidad o un proceder efectivo del agente (parcialidad) que, por su incompatibilidad con una cualidad o proceder deseable (o prescrito) asociado a la función pública que ejerce (imparcialidad), es presentado como una conducta o acción reprobable. Fundamentalmente, puesto que la máxima comporta una cierta instrucción pragmática, que se expresa en la conclusión final, el modelo supone la actitud que el esquema argumentativo producirá en el alocutario o espectador: la desaprobación del proceder del funcionario público.

También Meyer, del mismo modo que se desprende de la AMT, sostiene que el topos "es formal y material al mismo tiempo” (2013: 134): es formal en tanto que principio inferencial (propio del logos), es material en tanto que privilegia las respuestas previas (ethos) o busca aquellos valores compartidos por el auditorio (pathos). Desde la perspectiva problematológica, Meyer señala que "todo el arte del orador consiste en apoyarse sobre lo que no es problemático para él y para el auditorio; se lo llama topoi o lugar común, que permite transformar lo problemático en resolutorio y pasar de lo uno a lo otro” (Meyer, 2013: 102).

En la fotografía de Griesa, el topos invocado en tanto que valor es claramente no problemático, pues se presupone que está fuera de discusión que la neutralidad de los jueces es indispensable para el correcto funcionamiento de las instituciones judiciales. Asimismo, el topos en tanto que principio formal de inferencia, despliega la oposición entre lo que sería el comportamiento esperable de un juez (el valor en términos de Meyer) y el dato que se presenta en la fotografía, que desenmascara el "verdadero rostro" de Griesa en tanto que "buitre”. Se reduce así la distancia con un auditorio que comparte la desconfianza hacia dicho juez, puesto que se lo presenta como parcial de manera extrema: es parcial en el acto mismo de juzgar. Pero, ¿cómo se produce este efecto de sentido?

Pensar el topos como un elemento relacional de carácter gradual puede ayudarnos en este caso. En La argumentación en la lengua, Ducrot y Anscombre (1994) definieron el topos 
como "un tercer término, un garante, que autoriza el paso de A (argumento) a C (conclusión)” (217). En otro lugar, Anscombre (1995) destaca que el topos es común (presupuesto compartido por locutor y alocutario) y general (no se reducen a la situación de discurso que las utiliza). ${ }^{9}$ Pero lo que resulta específicamente distintivo de esta noción de topos tal como la define la teoría de la argumentación en la lengua, es su carácter gradual. El topos establece, para los lingüistas franceses, una correspondencia entre gradaciones, entre escalas no numéricas. Por ejemplo, el trabajo puede ser la medida del éxito o la del cansancio según el topos que se active. Pero es constitutivo del lexema trabajo, en un sentido estructural, poder relacionarse con cualquiera de esas gradaciones (éxito/cansancio) por medio de los topoi que él admite: por ejemplo, a más trabajo más cansancio, o a menos trabajo menos cansancio.

Esta condición de los topoi permitirá poner en evidencia un último aspecto escenificado por la fotografía de Griesa que corre peligro de pasar desapercibido en la reconstrucción de los esquemas argumentativos anteriores. El elemento que la gradualidad de los topoi ilumina en este ejemplo es el caso extremo de identidad entre juez y parte que establece la fotografía. Efectivamente, no solamente la imagen identifica a Griesa con los "fondos buitre”, sino que lo identifica con ellos en tanto que juez. Es clave el papel que juega la toga en la producción de este efecto de sentido: pues Griesa se convierte en buitre mientras se viste con la toga. Así, lo que es el símbolo institucional de la neutralidad del juez, se convierte en la marca distintiva de su filiación con una de las partes. Esto construye lo inadmisible de dicha identificación así como su expresión de grado extremo:

(Griesa) es juez SIN EMBARGO es parcial (buitre), INCLUSO es parcial (buitre) al momento de juzgar (cuando viste la toga) ${ }^{10}$.

\footnotetext{
9 “A este garante del paso del argumento a la conclusión llamaremos topos, en homenaje a Aristóteles, que ya en Los Tópicos formula una hipótesis muy parecida (véase también Toulmin y Perelman). ¿Qué son estos topoi? Son principios ideológicos, compartidos por una comunidad lingüística más o menos extensa, y que si bien sirven para la construcción arbitraria de representaciones ideológicas, se presentan siempre como si fueran exteriores al locutor, y por consiguiente, totalmente objetivos” (Anscombre, 1995:. 301).

${ }^{10}$ No pretendemos utilizar los conceptos de Ducrot para analizar las frases que nosotros mismos creamos a partir de lo visual; materialidad de sentido que carece, por otra parte, de unidades como los operadores argumentativos que constituyen el núcleo de la teoría de la argumentación en la lengua. Antes bien, su uso responde a la voluntad de que la transcripción (o transposición) a lo verbal se efectúe de acuerdo con una teoría argumentativa del lenguaje, de modo que la frase producida para dar cuenta de la imagen sea lo más transparente posible en cuanto a su orientación
} 
Pese a que no pueden existir en una imagen unidades que cumplan la función de operadores argumentativos como sin embargo o incluso, nos servimos aquí de ellos con fines descriptivos para marcar, en primer lugar, la oposición (sin embargo) -que ya se había expuesto en el esquema de la AMT con el lugar de los opuestos- y, luego, el encarecedor (incluso) del punto de vista con el que se identifica el locutor -la parcialidad. Si cuanto más parcial es una persona menos apto resulta para juzgar sobre la causa, la identidad total de Griesa con una de las partes al momento mismo de oficiar como juez, representado por el acto de portar la toga mientras se transforma en buitre, no puede llevar sino a concluir acerca de lo ilegítimo de su proceder.

El efecto encarecedor (incluso) respecto de la parcialidad del juez se produce por medio de una operación significante enteramente visual: ese elemento que es el símbolo de la neutralidad del juez (la toga) se convierte en el distintivo que lo identifica con la parte. En este sentido, contrapone elementos que corresponden a topoi opuestos: “un juez debe ser neutral” y “quien usa distintivos o uniformes se identifica con un bando". En el modo visual propio de una fotografía, todos los elementos coexisten, por lo que el efecto encarecedor no es un agregado pospuesto que obliga a una relectura del primer argumento como sucede con la linealidad sintagmática del lenguaje en uso. ${ }^{11}$ Sin embargo, la identificación entre juez y parte en tanto que "buitres” que se establece, junto con otros elementos (pose encorvada, joroba, etc.), por medio de la toga convertida en el ala del ave carroñera, produce un efecto de degradación del uniforme como atributo del juez: aquello que debería simbolizar la igualdad ante la ley garantizada por el sistema judicial acaba por ser el distintivo que lo identifica con una de las partes del juicio. La toga, uno de cuyos pretendidos propósitos es el de difuminar las diferencias individuales bajo el uniforme de la función, es lo que aquí revela lo que

argumentativa. Más adelante se intenta describir el modo en que este efecto de grado extremo se produce a través de procedimientos exclusivamente visuales.

11 'La ocurrencia de este conector (incluso), tradicionalmente calificado de reforzador, presenta una proposición p', generalmente posterior, como un argumento más fuerte que otra(s) proposición(es) $p$ anterior(es) a favor de una cierta conclusión r" (García Negroni y Tordesillas, 2001:.229). 
debería mantenerse no solamente oculto sino también anulado: la afinidad con la parte involucrada. $^{12}$

Por tratarse de una operación retorizante, la figura empleada alberga además una cierta ambivalencia: Griesa es tanto un juez disfrazado de buitre como un buitre disfrazado de juez; lo que admite que se desplace la cuestión sobre la orientación de su fallo presumiblemente favorable a los "fondos buitre"- hacia otra más amplia de si es efectivamente un juez competente -“no es un juez sino que sólo aparenta serlo”, sentido que encuentra un eco en los discursos que sostienen que el fallo de Griesa que impide a los bonistas reestructurados recibir los pagos realizados por Argentina es injustificable desde un punto de vista legal.

Por último, hay elementos en la fotografía que si bien no se han hecho intervenir de manera directa en el esquema argumentativo descripto, agregan sentidos no solamente complementarios al mismo sino que amplifican su alcance sensiblemente. Los edificios y la bandera estadounidense, en el marco del esquema argumentativo desplegado por la fotografía, pueden ser interpretados como la vinculación entre el poder corporativo y el poder judicial en Estados Unidos, tesis sostenida en ocasiones de manera velada y otras veces explícita por ciertos miembros del gobierno argentino involucrados en las negociaciones así como por sectores de la prensa. Pero el elemento clave, que dispara la lectura en clave conspirativa, es el par de manos que colocan sobre el juez la toga. No se alcanza a observar en el encuadre de la fotografía quién es el que “inviste” a Griesa, por lo que las manos adquieren ese cariz anónimo, abstracto, de aquel que es verdaderamente intocable. ¿Es el poder que opera detrás de bambalinas?

Los brazos que lo visten no tendrían nada que ver con el desempeño de Griesa como juez si no fuera porque la cuestión reside precisamente en si es imparcial o si por el contrario defiende intereses particulares. El par de brazos funciona como una sinécdoque generalizante: Griesa recibe su poder y su mandato del poder financiero

\footnotetext{
${ }^{12}$ En este sentido, una hipotética fotografía que mostrara a Griesa compartiendo alegremente una comida con Paul Singer (responsable del fondo de cobertura Elliott Management), contaría sin dudas con un poder testimonial que no posee la Fotografía 1, sin embargo, lo implicaría solamente en tanto que hombre privado. Se podría acusar a Griesa de ser parcial por tener una relación de amistad con una de las partes del juicio, pero no se produciría el efecto de sentido que se da aquí de que necesariamente será parcial en el acto mismo de juzgar.
} 
trasnacional, puesto que el modo en que las manos le colocan la toga sobre el cuerpo hace que en lugar de parecer un juez, se convierta en buitre. La fotografía constituye un conjunto orgánico en el que intervienen las dimensiones icónica (Peirce 1986) -la semejanza Griesa/buitres-, indicial -la relación de contigüidad entre los brazos y, por un lado, Griesa, al que manejan, y el poder oculto del que solo se ven indicios- y simbólica -la bandera norteamericana, los edificios como sede del poder corporativo-, que la orienta argumentativamente como una crítica feroz sobre dos de los tres actores involucrados en el juicio: el juez Griesa, y una de las partes, los “fondos buitre”.

Pese a que el procedimiento de la fotografía es, en términos de Meyer, retorizante, contiene de manera germinal o condensada aquellos principios que, según el propio Meyer, constituyen la quintaescencia del razonamiento argumentativo: "se trata de localizar lo que es idéntico, aún a título puramente analógico; o se trata también, por trabajo de redefinición, de sacar consecuencias, de destacar las cadenas causales que emanan de esas identidades y, por último, de señalar las diferencias, que pueden llegar hasta la oposición” (121).

En tanto que operación retorizante, la imagen se propone como respuesta a una cuestión dada, que parece no plantearse puesto que se la considera resuelta de antemano. Esta cuestión no es en realidad si el fallo de Griesa será favorable o desfavorable para la Argentina. El fallo del juez podría conferir la razón en la causa a los “fondos buitre” por cuestiones estrictamente legales, referidas de forma exclusiva a la aplicación técnica de las leyes pertinentes. Esta no es la cuestión de base respecto de la que la imagen es la respuesta, si bien, es evidente que orienta hacia la conclusión de que el fallo no será favorable a los intereses del país. La quaestio es, entonces, ¿es Griesa un juez idóneo para el seguimiento de esta causa? $\mathrm{Y}$ la respuesta que la imagen ofrece es contundentemente negativa: en tanto se identifica de manera completa con una de las partes, no es apto para fallar en el juicio. La legitimidad de Griesa como juez es lo que rechaza la fotografía. Es más, la fotografía se alinea con el discurso que no ve en Griesa otra cosa que un agente al servicio de los intereses de los “fondos buitre” y del capital financiero trasnacional. 


\section{Merkel y la NSA}

En este apartado se analizará una fotografía de Angela Merkel y su relación con el texto escrito que la acompaña en una noticia de la edición online del periódico The Guardian, correspondiente al supuesto conocimiento del gobierno alemán acerca de la masiva intervención de las comunicaciones llevada a cabo por la NSA americana en aquel país.

\section{News > World news > Edward Snowden}

\section{Edward Snowden tells Der Spiegel NSA is 'in bed with the Germans'

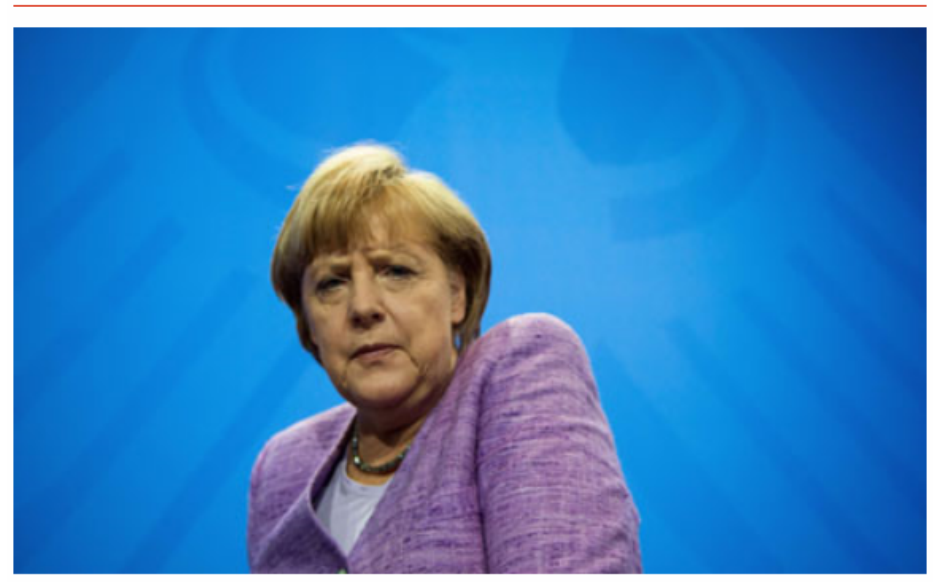

German opposition parties insist that somebody in Merkel's office must have known what was going on. Photograph: Johannes Eisele/AFP/Getty Images

Figura 2 - "Edward Snowden le cuenta a Der Spiegel que la NSA está 'en la cama con los alemanes””, theguardian.com, 7 de julio de 2013

De entrada, se hace patente que la correcta interpretación de la imagen en el contexto de la noticia que aquí se analiza no puede prescindir del componente lingüístico, compuesto esencialmente por el titular, la bajada, el epígrafe y, en menor medida, el conjunto de la nota. El titular de la nota delimita el tema de la misma: "Edward Snowden le cuenta a Der Spiegel que la NSA está ‘en la cama con los alemanes'”, y el epígrafe de la fotografía completa: "Partidos opositores alemanes insisten que alguien en el equipo de Merkel tiene que haber estado al tanto de lo que estaba sucediendo”. A partir de lo expresado por el componente escrito de la noticia, se orienta la 
interpretación de la imagen como representando a la canciller alemana en la acción de espiar a los ciudadanos, aunque evidentemente, no sea esa la acción que está realizando en la fotografía.

Pero antes de llegar a esta conclusión, y para fundamentar la lectura desde una perspectiva analítica, se describirán aquellos mecanismos semióticos a partir de los cuales la imagen refuerza estos sentidos vehiculizados por el texto escrito; se analizará también cómo, a través de medios expresivos propios, genera otros significados nuevos; y finalmente se detallará el lugar que cada modo semiótico ocupa en la economía discursiva de la noticia considerada como un paquete significante multimodal. Por otra parte, se hace necesario aquí, más aún que en el caso de la fotografía de Griesa, un análisis más detallado de la imagen en tanto que ésta no se encuentra estructurada en torno de una figura retórica de manera tan clara y unívoca como la precedente. Por ello, el análisis se valdrá de algunas de las categorías de la teoría que Kress y Van Leeuwen (1996) desarrollaron a partir de la gramática funcional de Halliday para la interpretación de las imágenes.

Comenzaremos con aquellos aspectos que definen la relación entre imagen y observador, es decir, aquellos aspectos que Kress y Van Leeuwen clasifican dentro de la metafunción interactiva: contacto, distancia, perspectiva y modalidad. A través de la mirada a la cámara se establece un contacto explícito con el observador, quien es invitado a tomar parte de una relación interpersonal con el principal participante representado en la fotografía: Angela Merkel. La mirada a la cámara establece esta relación imaginaria con el observador y genera un tipo de contacto denominado de demanda, por parte del participante. El encuadre modula una distancia que está a mitad de camino entre un plano cerrado y un plano medio, que se define comúnmente como un plano medio corto. Es decir, no entabla una mera relación social con el lector (correspondiente a un plano medio) sino que tiende hacia una relación algo más íntima (plano cerrado), reforzada por la intensidad de la mirada a cámara.

El ángulo de la fotografía no es plenamente frontal (el participante es retratado levemente perfilado). La conjunción del uso de este ángulo con la mirada a la cámara puede interpretarse, según Kress y Van Leeuwen, como si el participante dijera al observador: "pese a que no soy parte de tu mundo, de todos modos establezco un contacto contigo, desde mi propio mundo que es diferente” (1996: 138). Este rasgo de la 
imagen refuerza la idea de que se ha franqueado un límite, en este caso, el límite entre diferentes esferas de la sociedad: la extensión del accionar del Estado sobre la vida privada de la sociedad civil (connotando sentidos como “vigilancia”, “invasión”). Más que representar una invitación al lector de pasar a hacer parte del mundo retratado en la imagen, implica una expansión o prolongación de la esfera de acción del participante por sobre la esfera personal del observador. En este sentido, la mirada a la cámara genera un tipo de demanda particular, asimilable a lo que Jewitt y Oyama describen como una "demanda de deferencia, mirando a los observadores hacia abajo y sin pestañar” (2001: 145). Este efecto de sentido es producido por el punto de vista: el ángulo vertical bajo (contrapicado) coloca al participante representado en la posición de poder. Es él quien detenta la potestad de franquear los límites en la relación con el observador y tener una incidencia efectiva en su vida: tiene el poder de invadir la intimidad del destinatario.

Si bien se trata de una fotografía en la que encontramos una estética naturalista estructurada en términos de figura/ fondo, se podría hablar asimismo de una cierta modalidad abstracta en la fotografía, al menos dentro de los cánones genéricos del discurso de la información que es, en definitiva, el que nos ofrece la clave en la que esta imagen debe ser interpretada. La ausencia de contexto, de profundidad y de colores modulados en el fondo, tienden a la generación de significaciones subjetivas: "lo verdadero del color plano es una verdad abstracta, mientras que lo verdadero en el color modulado es una verdad naturalista, perceptual” (2002: 358). Si bien se puede sostener que la foto está descontextualizada, no es menos cierto que se puede inferir que la ocasión en la que se tomó la fotografía fue la de un acto o reunión oficial, lo que se puede obtener por algunos indicios como la ropa que lleva puesta la Canciller alemana o el escudo de armas de la República Federal de Alemania que se divisa en el fondo.

Hay, así, dos valores de modalidad conjugados en la misma imagen, cuya configuración viene a corroborar que “las imágenes son polifónicas, entretejiendo elecciones provenientes de distintos sistemas de significación, diferentes modos de representación, 
en una sola textura” (Kress y Van Leeuwen 1996: 172$).{ }^{13}$ Si la estética abstracta del color no modulado aplica al águila (el otro participante representado en la imagen), la estética naturalista del color modulado aplica a la imagen de Merkel y, como veremos a continuación, esta doble estética, o doble configuración de modalidad para ser más precisos, y sus significados asociados, es reforzada por los criterios composicionales que estructuran la imagen.

Para poder analizar esto, pasemos ahora a la metafunción composicional o textual. La figura de Merkel se recorta sobre un fondo azul en el que se distingue, por encima y alrededor de ella, a un segundo participante: el "águila federal"; símbolo de poder que, pese a haber sufrido varios cambios a lo largo de la historia, remonta su existencia a los días del Sacro Imperio. La noción de valor de información de una imagen refiere justamente a la colocación y disposición de los elementos representados dentro de una composición visual. Esta imagen se encuentra organizada en torno del eje arriba/abajo así como, en menor medida, en torno de la relación centro/margen. Lo ideal aparece arriba (el escudo de armas en un fondo no modulado y símbolo abstracto que representa el poderío de la nación alemana) y lo real, la imagen fotográfica de Angela Merkel, abajo: la figura de su gobernante de turno, concreto, que ejerce dicho poder para invadir la intimidad de la sociedad civil.

Pese a que la parte superior se presenta como general e idealizada, no es lo más saliente, ya que el águila aparece en el mismo color que el fondo, la diferencia está dada por la escala de valor: el color es algo más claro y menos saturado que el resto del fondo (como una marca de agua). La parte inferior, pero también el centro de la imagen, están tomadas por la figura de Merkel que se destaca del fondo con un alto contraste de brillo y color. El hecho de que esté colocada en el centro la convierte en una suerte de emanación del águila (o el águila es el respaldo del aparato del Estado detrás de ella), donde las alas de aquella quedan situadas a los lados del cuerpo del participante, como si fueran un atributo de éste. A nivel de la metafunción representacional se podría hablar

\footnotetext{
${ }^{13}$ Las imágenes, dicen Kress y van Leeuwen, "pueden ser abstractas respecto de un marcador de modalidad, naturalistas respecto de otro y sensoriales respecto de un tercero, y esto permite una multiplicidad de configuraciones de modalidad" (1996: 171).
} 
de un proceso conceptual simbólico atributivo (más allá de que el proceso principal de la imagen pueda ser narrativo). Por eso, si bien el águila está colocada arriba y en los márgenes, la delimitación entre participantes parecería estar más dada por la relación figura/fondo, ya que no hay líneas divisorias. Aunque estén bien demarcadas ambas figuras (existe una estructuración fuerte), éstas constituyen, a nivel textual, una unidad significante.

El análisis precedente nos permite reflexionar ahora sobre el sentido y la orientación argumentativa de esta imagen, la relación con sus condiciones de producción, y sobre la interacción compleja que mantiene con otros modos semióticos como el lenguaje en el marco de la noticia periodística en la que se inserta.

Consideremos primero la cuestión acerca de las condiciones de producción de la imagen. Si bien se puede inferir (como se expuso más arriba) que la fotografía haya sido tomada en ocasión de una conferencia de prensa o de una reunión oficial con otros líderes políticos, no se dice nada acerca de su origen en el epígrafe ni tampoco en el cuerpo de la nota. En un primer nivel de análisis, la fotografía parecería cumplir una función meramente ilustrativa de aquello que es el tema de la noticia: el Estado alemán tenía conocimiento y participaba activamente en el espionaje de las comunicaciones privadas de la sociedad civil. Se trataría de lo que Verón (1994) denominó en su análisis de las fotografías periodísticas como "retórica de las pasiones”: “el 'estado de ánimo' del político, captado por una instantánea de su rostro, sirve para calificar una coyuntura política determinada” (60). En contraposición con otros tipos de fotografía periodística identificadas por Verón (como la pose, la testimonial o la categorizadora), aquí la foto está anclada en el presente de la actualidad, que "nada tiene que ver con las condiciones de la producción de la fotografía: las circunstancias en las que fue tomada, lo que el político en cuestión hacía en ese momento, etc., no tienen ninguna importancia: todos los reenvíos indiciales se suspenden” (60). En este caso, la fotografía seleccionada por The Guardian del banco de imágenes de Getty Images, fue tomada cuatro días antes, en ocasión de la Cumbre Europea de Desempleo en Jóvenes que tuvo lugar en Berlín y a la 
que asistió Angela Merkel, junto con otros políticos, como el presidente francés François Hollande. ${ }^{14}$

Queda claro que la fotografía fue utilizada con una intención diferente de aquella con la que fue producida, lo que es, por otra parte, una actividad muy común en la fotografía periodística y es el caso asimismo de la fotografía de Griesa que se analizó antes. Kress y Van Leeuwen señalan, recordando los trabajos de Stuart Hall, la manera en que este tipo de fotografías, esto es, planos cortos de reactores no transaccionales en los que no se ve a lo que miran, ${ }^{15}$ se utilizan para ejercer esta manipulación representacional en las fotografías de prensa de políticos. En estas fotografías "una frase puede, por ejemplo, sugerir aquello a lo que el Reactor está mirando, pero, no hace falta decirlo, no es necesario que sea aquello a lo que el Reactor estuviera efectivamente mirando cuando la fotografía fue tomada” (1996: 68).

Pero en el caso de la fotografía de Merkel, eso no es todo lo que sucede. En efecto, en la imagen aquí analizada hay, además, una operación de figuración, puesto que se significa o se pone en escena una acción (espiar) construida sobre la decodificación canónica de la mirada a la cámara, la que entabla una relación metonímica entre participante y destinatario (Verón 1983, 1998). En un nivel referencial, Merkel observa a la cámara, en otro nivel, figurado, observa a cada uno de los lectores que, a su vez, son los ciudadanos espiados de los que habla el texto de la nota. La acción de espiar y la de mirar a la cámara -mirada a través de la que se establece una relación entre participante representado y observador- son una y la misma cosa. ¿Y cómo es que la mirada a la cámara significa “espiar”? La lectura de la mirada en este sentido es garantizada por la composición visual de la imagen que ya analizamos y, desde luego, por la estructuración de la polisemia de la imagen que efectúa el componente lingüístico.

\footnotetext{
${ }^{14}$ La imagen utilizada contrasta, por otra parte, con la fotografía testimonial elegida por Der Spiegel -la noticia del periódico inglés tiene su origen en una entrevista que la revista alemana Der Spiegel realizó a Edward Snowden-, en la que se puede ver una protesta en Berlín en la que los manifestantes llevan máscaras con el rostro del ex analista de la CIA: http://www.spiegel.de/international/world/edward-snowden-accuses-germany-of-aiding-nsa-in-spyingefforts-a-909847.html.

${ }^{15}$ Esto es a nivel de la metafunción representacional, que no se trató aquí en beneficio de un desarrollo mayor de las otras dos. Utilizando la terminología de Kress y Van Leeuwen, es un proceso narrativo reaccional no transaccional, aunque también hay al menos un proceso conceptual simbólico como se mencionó antes.
} 
Esto nos lleva al segundo punto: la relación de la imagen con el texto escrito. La protagonista excluyente de la fotografía es Angela Merkel, sin embargo, no se la menciona en el titular de la nota. Sí se la nombra en la bajada y en el epígrafe, pero no en tanto que agente activo en las actividades de intervención de las comunicaciones, sino simplemente en tanto potencial conocedora de lo acontecido. De esta manera, la imagen, si bien podemos decir que presenta a Merkel como máximo responsable del gobierno alemán y en ese sentido justifica su lugar de prominencia en la misma, se centra mucho más en su figura de lo que lo hace el texto escrito, y la presenta en otros términos: como agente directo de la intervención. Al mismo tiempo, el carácter fuertemente interactivo que adquiere la imagen por el uso de la mirada a la cámara, no tiene su correlato en una apelación directa al destinatario a nivel del texto escrito, que se circunscribe a los estándares del artículo periodístico.

Pero la relación entre texto e imagen juega un rol que va incluso más allá del nivel composicional de la noticia. Es sólo a través de la imagen que el enunciador (el soporte o medio, es decir en este caso, The Guardian) toma a su cargo un enunciado que no puede sostener desde lo escrito, al menos no sin marcas de evidencialidad: que el gobierno alemán (incluida Angela Merkel) espía a sus ciudadanos. ${ }^{16}$ Esto se relaciona directamente con la vida social y, podríamos incluso decir, el accountability al que cada modo semiótico, en el marco de un género o tipo de discurso específico, se encuentra sometido, esto es, los contenidos que puede acarrear y las sanciones de las que puede ser objeto.

Del mismo modo que sucede con la fotografía del juez Griesa, se presupone que Merkel en tanto que canciller, es depositaria del mandato popular, por lo que debería obrar en el mejor interés de los ciudadanos y guardarse de no avasallar los derechos de estos últimos. El dato de la imagen, que se opone a ese esperable, nuevamente se escenifica a partir una figura retórica: "En vez de decirlo tal cual, el tropo enuncia como respuesta

\footnotetext{
${ }^{16}$ Si analizamos el texto encontramos una cita en el titular: "Edward Snowden le cuenta a Der Spiegel que la NSA está 'en la cama con los alemanes". Una conjetura en la bajada: "Entrevista llevada a cabo antes de que el denunciante de la NSA huyera hacia Hong Kong aparenta contradecir la sorpresa pública de Merkel sobre el espionaje” y la atribución de las declaraciones a terceros en el epígrafe a través del uso del discurso indirecto: "Partidos opositores alemanes insisten que alguien en el equipo de Merkel tiene que haber estado al tanto de lo que estaba sucediendo”. Otro tanto sucede en el resto del texto en el cuerpo de la noticia.
} 
algo que sugiere una respuesta distinta que él permite inferir” (Meyer 2013: 153); pero justamente, esa respuesta nunca aparece explicitada en la superficie textual, sino que queda a cargo del destinatario reponerla.

\section{Conclusiones}

A modo de palabras finales, solo queda enfatizar que el periodismo y, puntualmente, las líneas editoriales de la prensa escrita ejercen un control y sanción de la vida política a través de un despliegue multimodal del discurso que orienta argumentativamente una representación ideológica. Ciertamente, este despliegue es sutil, como hemos querido mostrar, ya que la línea editorial se cuidará de no caer en obviedades que le puedan significar reproches públicos por parte de los protagonistas de las noticias o, más importante, acusaciones legales que dañen su imagen y tengan un perjuicio económico.

La retórica de la imagen periodística, cuando la situación lo amerita o los intereses corporativos de la compañía se sienten llamados a intervenir, se manifiesta robusta desde el punto de vista semiótico, tajante desde el punto de vista argumentativo, y estratégica desde el punto de vista estético. Los dos casos aquí analizados así lo han demostrado, poniendo en esa a un interlocutor, o audiencia, que debe, no obstante, completar el sentido incorporando la información contextual. Sin embargo, lo más evidente en este aparente juego interpretativo, es que la audiencia vería confirmada su posición ya sancionada públicamente: el castigo al actor político o social. Es a partir de estas fórmulas que la línea editorial impone un punto de vista, asegura protagonismo público, y obtiene réditos comerciales.

\section{Bibliografía}

Anscombre, Jean-Claude. (1995). Semántica y léxico. Topoi, estereotipos, y frases genéricas. Revista Española de Lingüística, 25, 297-310.

Anscombre, Jean-Claude y Oswald Ducrot. (1994). La argumentación en la lengua. Madrid, España: Gredos.

Barthes, Roland. (1997). La aventura semiológica. Barcelona, España: Paidós.

Benveniste, Émile. (1974). Problemas de Lingüística General II. México 2011: Siglo XXI Editores. 
van Eemeren, Frans y Rob Grootendorst. (2004). A Systematic Theory of Argumentation. The Pragma-Dialectical Approach. Nueva York, Estados Unidos: Cambridge University Press.

García Negroni, María y Marta Tordesillas Colado. (2001). La enunciación en la lengua. De la deixis a la polifonía. Madrid, España: Gredos.

Greco Morasso, Sara. (2011). The Challenge Of Studying Argumentation In Context. En van Eemeren, F.H., B. Garssen, D. Godden, y G. Mitchell (Eds.), International Conference of the International Society for the Study of Argumentation (ISSA): Proceedings (pp. 1-10). Amsterdam, Holanda: SicSat.

Grupo $\mu$. (1987). Retórica general. Barcelona, España: Paidós.

Jewitt, Carey y Rumiko Oyama. (2001). Visual meaning: a social semiotic approach. En van Leeuwen, T. y C. Jewitt, Handbook of Visual Analysis (pp. 134-156) Londres, Inglaterra: Sage.

Kress, Gunther y Theo Van Leeuwen. (1996). Reading Images. The Grammar of Visual Design. Londres, Inglaterra: Routledge.

Kress, Gunther y Theo Van Leeuwen. (2002). Colour as a semiotic mode: notes for a grammar of colour. Visual Communication, 1 (3), 343-368.

Metz, Christian. (1979). El significante imaginario. Barcelona, España: Editorial Gustavo Gili.

Meyer, Michel. (2013). Principia Rhetorica. Una teoría general de la argumentación. Buenos Aires, Argentina: Amorrortu Editores.

Peirce, Charles. (1986). La ciencia de la semiótica. Buenos Aires, Argentina: Nueva Visión.

Perelman, Chaïm y Lucie Olbrechts-Tyteca. (1989). Tratado de la argumentación. La nueva retórica. Madrid, España: Gredos.

Pollaroli, Chiara. (2012). Tropos y topoi: los esquemas argumentativos en los anuncios publicitarios. 1er Colloque franco-espagnol d'analyse de discours et didactique de langues. Le langage manipulateur: pourquoi et comment argumenter?, 13-15 sept. 2012, Arras, Francia. 
Rigotti, Eddo. (2008). Locus a causa finali. L'analisi Linguistica e Letteraria, XVI (2), 559-576.

Tindale, Chistopher. (2004). Rhetorical Argumentation: Principles of Theory and Practice. Londres, Inglaterra: Sage.

Toulmin, Stephen. (2007). Los usos de la argumentación. Barcelona, España: Ediciones Península.

Van den Hoven, Paul. (2011). Iconicity in Visual and Verbal Argumentation. En van Eemeren, F.H., B. Garssen, D. Godden, y G. Mitchell (Eds.), International Conference of the International Society for the Study of Argumentation (ISSA): Proceedings (pp. 831-834). Amsterdam, Holanda: SicSat.

Verón, Eliseo. (1983). II est là, je le vois, il me parle. Communications, 38, 98-120.

Verón, Eliseo. (1998). La semiosis social. Fragmentos de una teoría de la discursividad. Barcelona, España: Gedisa.

Verón, Eliseo. (1994). De l'image semiologique aux discursivités. Le temps d'une photo. En Veyrat-Masson, Isabelle y Daniel Dayan (Eds.), Hermès 13-14. Espaces Publics en Images (pp. 45-64). Paris, Francia: CNRS Éditions.

Walton, Douglas. (2008). Informal Logic: A Pragmatic Approach. Cambridge, Inglaterra : Cambridge University Press.

Žagar, Igor Ž. (2011). The Use and Misuse of Topoi: Critical Discourse Analysis and Discourse-Historical Approach”. En van Eemeren, F.H., B. Garssen, D. Godden, y G. Mitchell (Eds.), International Conference of the International Society for the Study of Argumentation (ISSA): Proceedings (pp. 2032-2046). Amsterdam, Holanda: SicSat.

Recibido: 8 de diciembre de 2014

Aceptado: 15 de junio de 2015

Publicado: 29 de febrero de 2016

Actualizado: 14 de marzo de 2016 